REVIEW ARTICLE

\author{
E.M. Lyders \\ C.T. Whitlow \\ M.D. Baker \\ P.P. Morris
}

\title{
Imaging and Treatment of Sacral Insufficiency Fractures
}

SUMMARY: SIFs are a common, though often unsuspected, cause of low back pain in the elderly. Although numerous radiographic modalities can be used to diagnose SIFs, bone scintigraphy and MR imaging are the most sensitive. Conservative management involves various combinations of bed rest, rehabilitation, and analgesics. More recently, sacroplasty has emerged as an alternative therapy for the treatment of SIFs, with prospective studies and case reports suggesting that it is a safe and effective therapy. This article reviews the imaging appearance of SIFs and discusses treatment options with a focus on sacroplasty.

ABBREVIATIONS: FEA = finite-element analysis; $\mathrm{MDP}=$ methylene diphosphonate; $\mathrm{PMMA}=$ polymethylmethacrylate; SIF = sacral insufficiency fracture; VAS = visual analog pain scale.

$\mathbf{S}^{\mathrm{s}}$ IFs are a common cause of debilitating back pain in the elderly. Since they were first described as a clinical entity in 1982 by Lourie, ${ }^{1}$ the awareness of this entity among health care professionals has increased. However, there is often a delay in diagnosis because clinical symptoms are frequently vague and nonspecific and can mimic a variety of pathologic processes in a predominantly elderly population, including radiculopathy and metastatic disease. Bone scintigraphy and MR imaging are the most sensitive studies to detect SIFs, though findings have been described in a wide variety of radiologic modalities. The standard of care for the treatment of SIFs has been conservative management, with variable courses of bed rest, rehabilitation, and analgesics prescribed..$^{2-4}$ More recently, sacroplasty, a minimally invasive procedure akin to vertebroplasty in the thoracolumbar spine, has been advocated as an alternative to conservative therapy. Retrospective case series and prospective studies suggest that sacroplasty is a safe and effective procedure, providing early symptomatic relief in patients with SIFs. ${ }^{5-8}$ This article discusses the imaging findings and treatment of SIFs.

SIFs commonly affect elderly women with osteoporosis, ${ }^{9,10}$ though other reported risk factors include pelvic radiation, steroid-induced osteopenia, rheumatoid arthritis, multiple myeloma, Paget disease, renal osteodystrophy, and hyperparathyroidism. ${ }^{2,9,11}$ Of these, osteoporosis is the most prevalent, and almost all patients with SIFs will demonstrate severe osteopenia on dual $\mathrm{x}$-ray absorptiometry, even if other risk factors are present. $^{2}$ Prior pelvic radiation is another wellestablished risk factor for the development of SIFs, with a reported prevalence of $21 \%-34 \% .^{12,13}$ The incidence may even be as high as $89 \%$, as suggested by a prospective study of patients undergoing pelvic radiation for cervical cancer. ${ }^{14}$

Almost all patients with SIFs are older than 55 years of age, with a mean age between 70 and 75 years in most studies. ${ }^{4,6,15,16}$ The true incidence of SIFs is unknown but has been

From the Division of Radiological Sciences, Department of Radiology, Wake Forest University School of Medicine, Winston-Salem, North Carolina.

Please address correspondence to P. Pearse Morris, MB, BCh, Division of Radiological Sciences, Department of Radiology, 2nd Floor, Meads Hall, Wake Forest University School of Medicine, Winston-Salem, NC 27157; e-mail: pmorris@wfubmc.edu

Indicates open access to non-subscribers at www.ajnr.org

DOI 10.3174/ajnr.A1666 reported to be between $1 \%$ and $5 \%$ in at-risk patient populations. ${ }^{17-19}$ Antecedent trauma is not identified in two-thirds of patients $^{3,4}$ and, when present, is usually minor. ${ }^{16}$

Patients with SIFs most commonly present with diffuse low back pain, which may radiate to the buttock, hip, or groin. ${ }^{3,15,20}$ Patients may have some tenderness to palpation in the lower back and sacral region, though this is not a consistent finding. ${ }^{15}$ Neurologic symptoms related to SIFs are unusual, though may be seen in $5 \%-6 \%$ of patients, most commonly manifesting as a sacral radiculopathy. ${ }^{2}$ However, a case of cauda equina syndrome related to SIFs has been reported. ${ }^{21}$

SIFs can occasionally be confused with metastatic disease, both clinically and on imaging studies, ${ }^{22}$ resulting in unnecessary work-up and biopsy. ${ }^{9-10}$ This is frequently a confounding factor in elderly patient populations, many of whom have a known primary malignancy or are being evaluated for an occult tumor. ${ }^{16,22,23}$ In fact, approximately $45 \%$ of patients with SIFs have a history of malignancy. ${ }^{2}$

Insufficiency fractures are a subtype of stress fracture that results from normal stress applied to abnormal bone that has lost its elastic resistance. Bone insufficiency is often the result of osteoporosis or other metabolic bone disease, though osseous metastatic disease and marrow replacement processes can also cause insufficiency fractures. SIFs most commonly involve the sacral ala, lateral to the neural foramina and medial to the sacroiliac joints (zone 1) (Fig 1). ${ }^{24}$ Fractures may be unilateral or bilateral and are reported with relatively equal frequency in the literature., ${ }^{2,9}$ There may also be a horizontal component to the fracture through the sacral bodies. This unique fracture pattern may be related to axial loading and weight-bearing transmitted through the spine, resulting in sacral alar strain. ${ }^{25,26}$ Additionally, osteoporosis causes asymmetric loss of bony trabeculae in the sacral ala compared with the vertebral bodies, placing the lateral aspect of the sacrum at increased risk of insufficiency. ${ }^{27}$

Of note, there is a high incidence of concomitant pelvic insufficiency fractures, and radiologists should be aware of this association. SIFs are most frequently associated with insufficiency fractures of the pubic rami and parasymphyseal region, with a reported coincidence of $88 \% .{ }^{9}$ Associated insufficiency fractures have also been described in the superior acetabulum and iliac wing. ${ }^{28,29}$ It has been suggested that the 


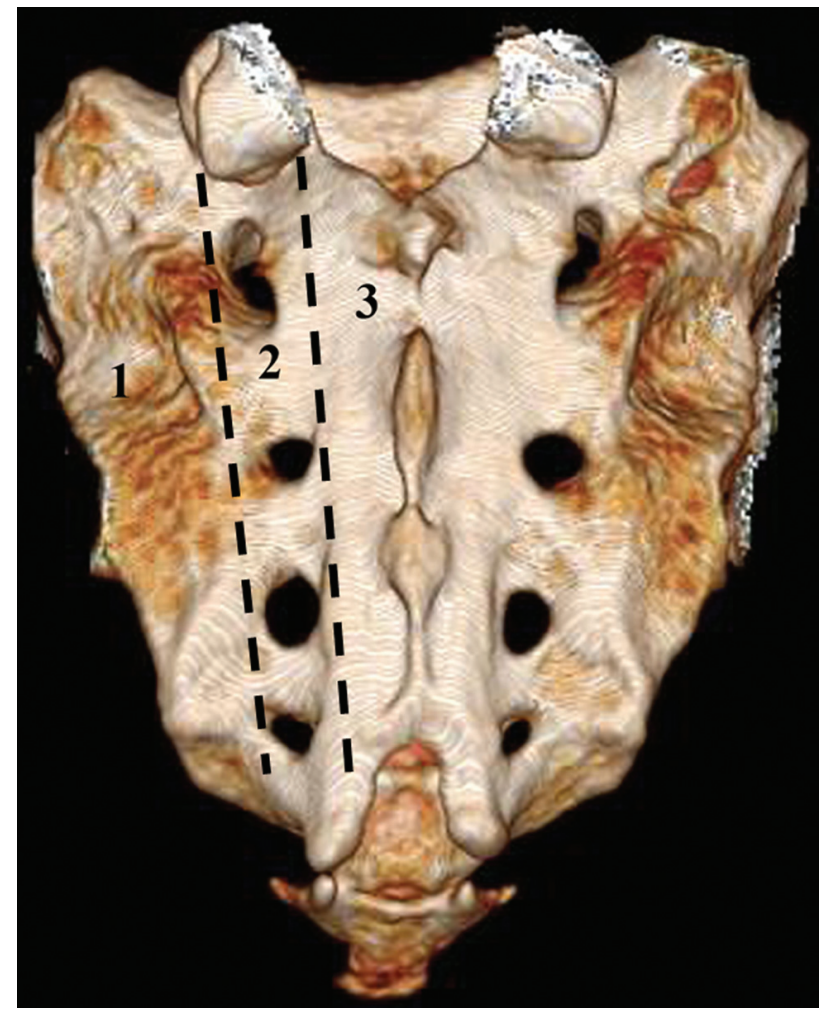

Fig 1. Posterior projection from a $3 \mathrm{D}$ volume rendered normal sacrum. Labels denote the classification system proposed by Denis et al. ${ }^{24}$ Zone 1 contains the sacral ala and portions of the sacrum lateral to the neural foramina. Zone 2 contains the foramina. Zone 3 contains the sacral bodies.

sacrum is the initial site of failure and that this results in increased stress on the rest of the bony pelvis. ${ }^{9}$

\section{Anatomy}

The sacrum is a triangular or shield-shaped bone at the caudal end of the spine comprising 5 vertebral segments. Denis et $\mathrm{al}^{24}$ divided the sacrum into 3 zones (Fig 1). Zone 1 is composed of the sacral ala and bone between the sacroiliac joints and the neural foramina and is the most common site of SIFs. Zone 2 contains the neural foramina, and Zone 3, the sacral bodies. The sacrum articulates with the iliac bones of the pelvis laterally, the lumbar spine superiorly, and the coccyx caudally. The sacral spinal canal extends along the length of the dorsal aspect of the sacrum (Fig 2). Of note, the thecal sac usually ends at S2.

\section{Imaging}

The imaging findings of SIFs have been well described in the literature and are reviewed below. However, initial imaging is often not targeted at the sacrum but rather at the lumbar spine and/or pelvis. In fact, there is often a delay of 40-55 days from symptom onset before dedicated sacral imaging is pursued. ${ }^{28}$

\section{Plain Films}

SIFs usually appear as vertical bands of sclerosis oriented parallel to the sacroiliac joints in zone 1 of the sacrum (Fig 3)..$^{29,30}$ Occasionally, cortical disruption and/or fracture lines may be evident. ${ }^{31}$ In one meta-analysis, sclerosis was reported in $57 \%$ of patients, with a fracture line evident in only $12.5 \% .^{2}$ On follow-up imaging, the time course of radiographic resolution

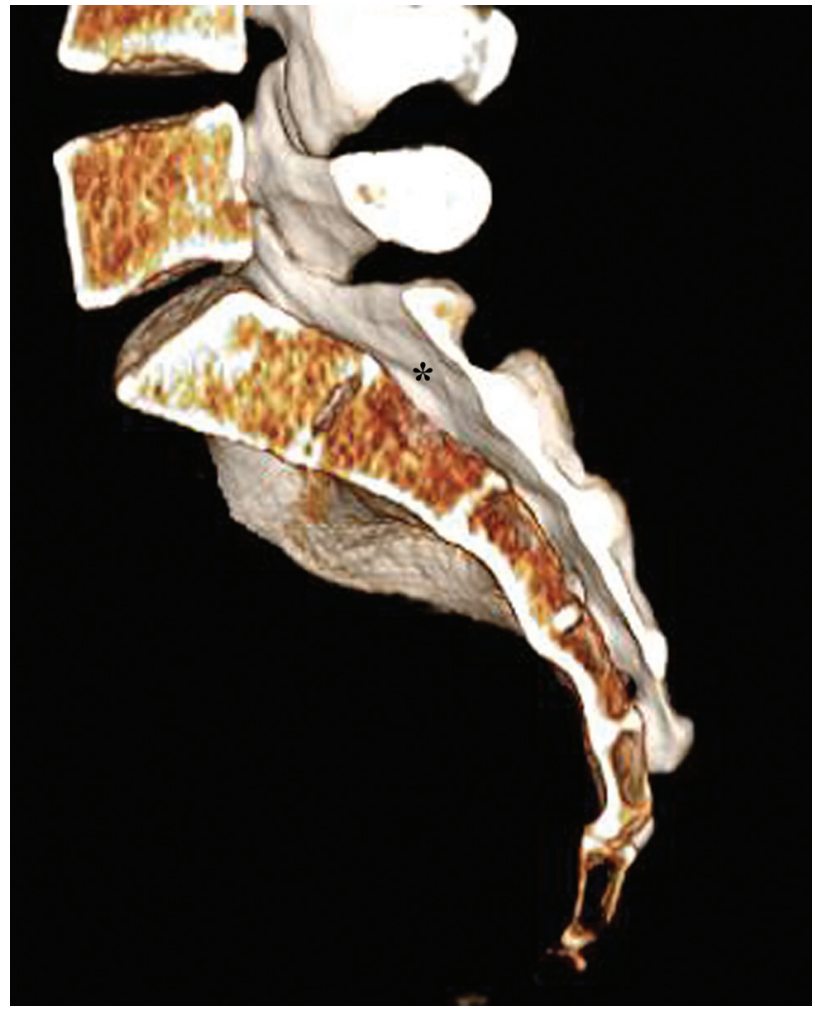

Fig 2. Lateral slab projection of a $3 \mathrm{D}$ volume rendered normal sacrum demonstrating the relationship of the central sacral canal (asterisk) in the sacrum.

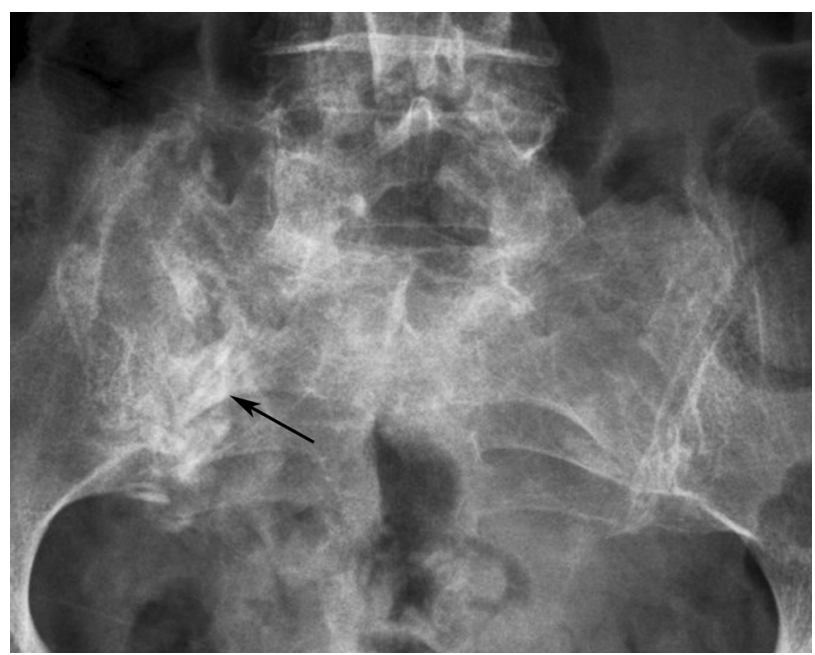

Fig 3. Coned-down anteroposterior radiograph of the lumbar spine demonstrates a right-sided SIF (black arrow) manifest as a band of sclerosis and a cortical break in the lateral aspect of the sacrum.

of sclerotic fracture lines is quite variable, ranging between 1 and 13 months. ${ }^{9}$

Occasionally fractures can have an aggressive appearance, simulating malignancy, with areas of sclerosis and periosteal reaction. This may lead to unnecessary work-up and biopsy, which can also be confused with an aggressive process pathologically. ${ }^{9,31}$

Plain films are, therefore, insensitive for the detection of SIFs, and dedicated radiographs of the sacrum are rarely acquired. More often, radiographs of the lumbar spine and pelvis are acquired in the initial work-up. Studies suggest that 


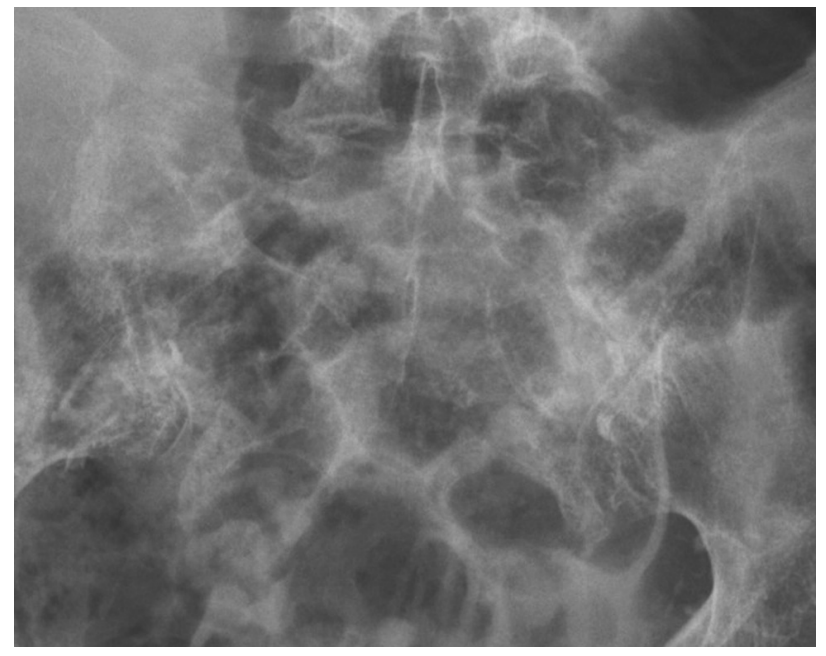

Fig 4. Bowel gas obscures a left SIF in this patient with osteoporosis on this coned-down anteroposterior radiograph of the pelvis.

only $20 \%-38 \%$ of SIFs and pelvic ring fractures are identified on plain films, ${ }^{2,4}$ and these are often overlooked prospectively. Even when evaluated retrospectively, less than $50 \%$ of SIFs diagnosed on bone scintigraphy were evident on plain films. ${ }^{32,33}$ SIFs may not be evident in a large percentage of patients because of a high prevalence of osteopenia and obscuration by overlying bowel gas (Fig 4$){ }^{31}$

\section{Nuclear Medicine}

Bone scintigraphy with technetium Tc99m-labeled MDP is one of the most sensitive examinations for the detection of SIFs, and the imaging findings have been well documented. ${ }^{2,33}$ Various patterns of radiotracer uptake have been described, with the so-called "Honda" sign or H-pattern considered diagnostic of SIFs in the correct clinical setting (Fig 5). ${ }^{33}$ However, this pattern of radiopharmaceutical uptake is seen only in $20 \%-40 \%$ of patients. ${ }^{4,31}$ Variations in the pattern of radiopharmaceutical activity in SIFs include uptake oriented unilaterally in the sacral ala, unilaterally with a horizontal strut, bilaterally without a horizontal strut, and as multiple foci of activity. ${ }^{34}$ Posterior planar images are the most sensitive (ie, when the sacrum is closest to the detector) ${ }^{29}$ Follow-up scintigraphic results are quite variable, with changes in the radiopharmaceutical uptake pattern during a 10- to 33-month interval, ranging from resolution of abnormal activity to no change or even worsening activity. ${ }^{3,9,22,31}$

Bone scintigraphy has a reported sensitivity of $96 \%$ for the detection of SIFs, with a positive predictive value of $92 \%{ }^{34}$ Some authors have suggested that characteristic patterns of uptake in the sacrum should be considered diagnostic in the correct clinical context, especially if there are no other sites of abnormal activity in the skeleton and no history of primary malignancy. ${ }^{33}$ However, there have been case reports of isolated metastases presenting as unilateral sacral uptake. ${ }^{34}$

\section{$C T$}

Similar to radiographs, CT may demonstrate sclerosis in the sacral ala and lateral sacrum paralleling the sacroiliac joints. Fracture lines with or without bony callous are evident in approximately $75 \%$ of patients (Fig 6). ${ }^{2}$ Fracture lines are usually
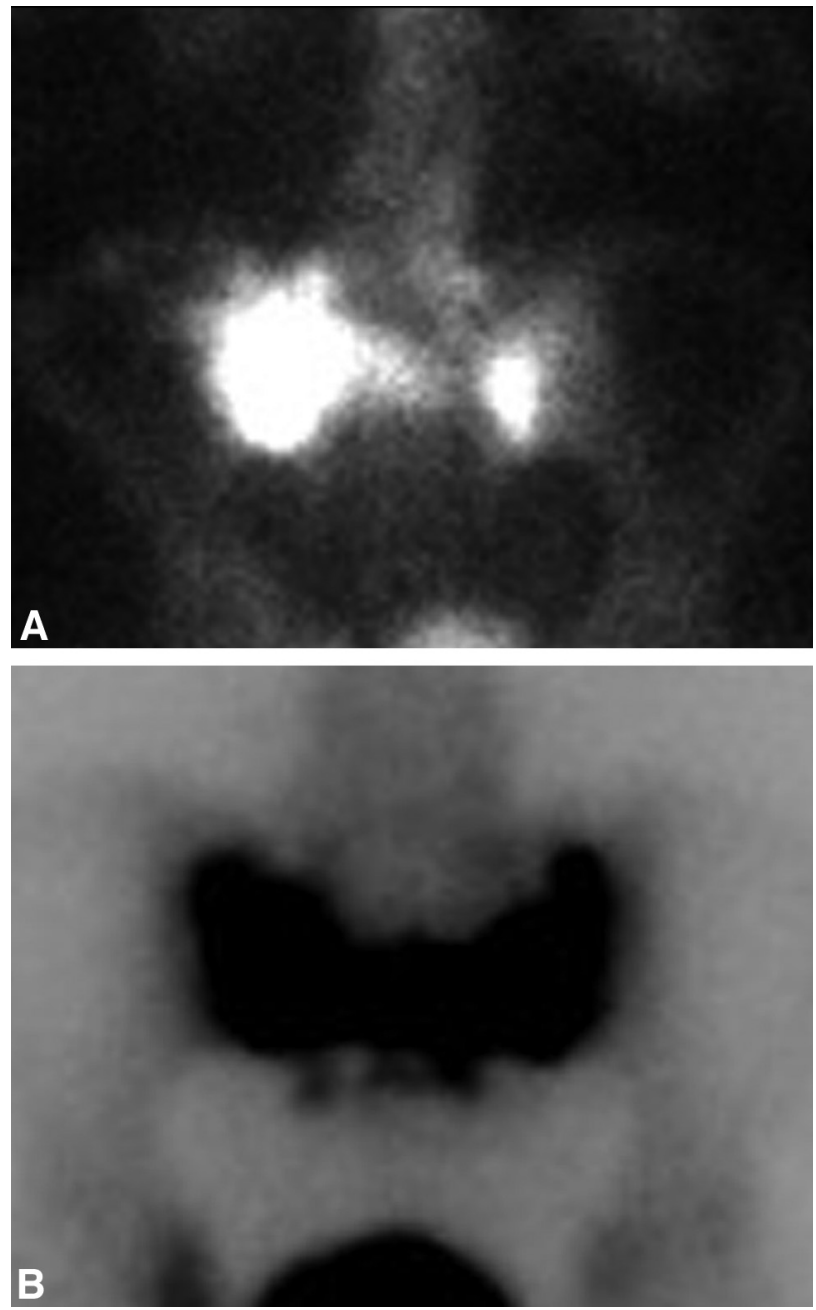

Fig 5. $A$, Posterior planar scintigraphic image from a Tc99m-MDP bone scan demonstrates asymmetric sacral uptake without a horizontal strut in the setting of SIF. B, Tc99m-MDP bone scan on a different patient demonstrates the classic Honda sign characteristic of SIFs. Note, incidentally, physiologic activity within the bladder in both cases.

sagittally oriented and are readily apparent on axial CT images; however, the full extent of the sacral fracture may not be evident if there is an isolated or significant horizontal component. For this reason, coronal images, either reformatted or directly acquired, may be helpful to visualize the full extent of the fractures. ${ }^{3}$

CT is not as sensitive for the detection of SIFs when compared with bone scintigraphy or MR imaging, with a reported sensitivity between $60 \%$ and $75 \% .^{2,35}$ However, CT may be helpful to confirm inconclusive or equivocal findings on bone scintigraphy or MR imaging. ${ }^{9,31}$ Visualization of bone detail on CT may also be useful to determine if the fracture lines extend into the neural foramina, creating a potential pathway for cement if sacroplasty is being considered as a treatment option. ${ }^{36} \mathrm{CT}$ can also be especially helpful when trying to differentiate fracture from metastatic disease because it can depict cortical destruction and/or a soft-tissue mass in cases of tumor involvement. $3,12,37$

\section{MR Imaging}

MR imaging can detect early changes of sacral insufficiency and, similar to bone scintigraphy, has a reported sensitivity at 

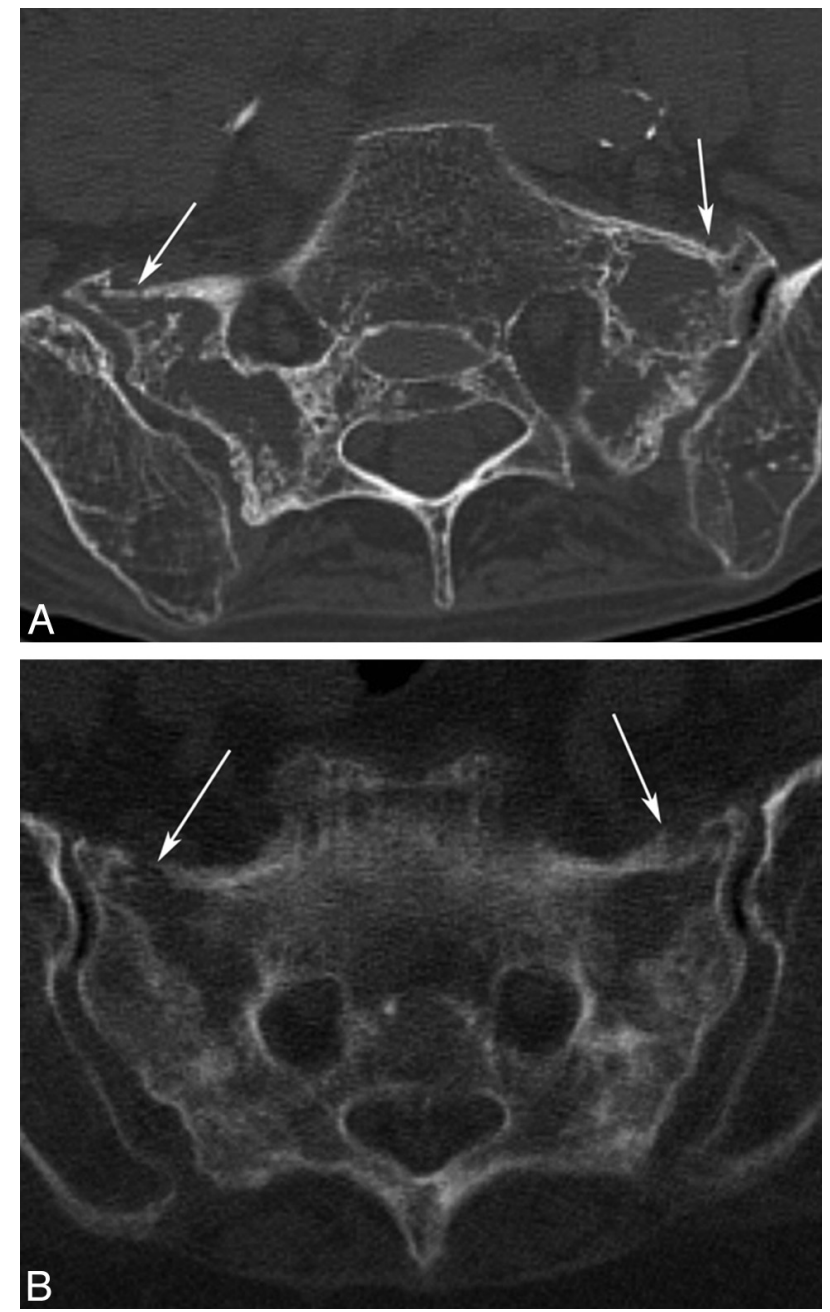

Fig 6. Axial CT scans of the pelvis in 2 different patients demonstrate bilateral SIFs (white arrows) with mottled sclerosis/lucency and cortical breaks.

or near $100 \% .^{35} \mathrm{~T} 2$ short $\tau$ inversion recovery sequences are exquisitely sensitive for the detection of early marrow edema related to SIFs, ${ }^{31}$ which can be seen as early as 18 days after symptoms develop. ${ }^{28}$ Most cases demonstrate both marrow edema and a fracture line. ${ }^{35}$ Marrow edema is demonstrated as areas of increased signal intensity on T2-weighted and inversion-recovery images and low signal intensity on T1-weighted images. ${ }^{28,35,38}$ A hypointense fracture line is usually evident within the area of edema, though it is not seen in $7 \%$ of cases (Fig 7$).^{35}$

Coronal oblique images in the plane of the sacrum better demonstrate the vertically oriented fractures and should be included in the imaging protocol if there is clinical suspicion (Fig 7). ${ }^{31}$ Unfortunately, most patients evaluated for back pain initially have undergone lumbar spine imaging, and coronal oblique imaging of the sacrum is not routinely performed. Again, radiologists should be aware of this pitfall when interpreting lumbar MR images of elderly patients.

MR imaging can usually differentiate marrow edema secondary to SIFs from malignancy, with fat-saturation and postgadolinium imaging being particularly useful in this regard. ${ }^{19}$ Occasionally, MR imaging can be confusing, especially if a fracture line is not evident, and correlative CT or follow-up imaging may be useful.
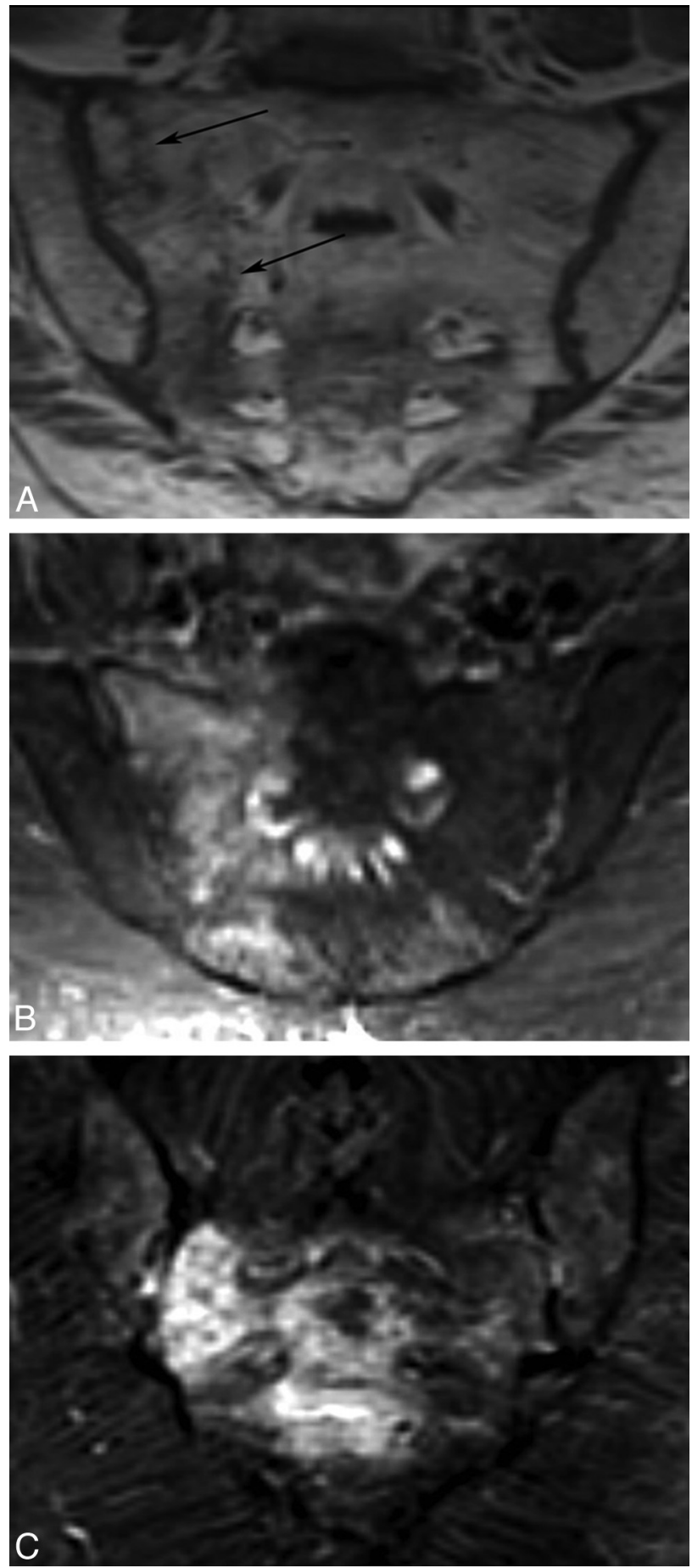

Fig 7. MR images in different patients with SIFs. $A$, Coronal oblique T1-weighted image demonstrates patchy low-signal intensity edema and a hypointense fracture line. $B$ and $C$, Coronal oblique inversion-recovery images demonstrate high-signal-intensity edema within the lateral sacrum. Note a horizontal component involving the sacral bodies in $C$.

\section{Treatment}

\section{Conservative Therapy}

Conservative management of SIFs has been the standard of care, though suggested treatment regimens are quite variable. Some authors recommend strict bed rest and pain control, ${ }^{2,3,10}$ whereas others suggest moderation of activity supplemented with crutches or a walker in addition to analgesics. ${ }^{16}$ There have also been reports promoting early physical 

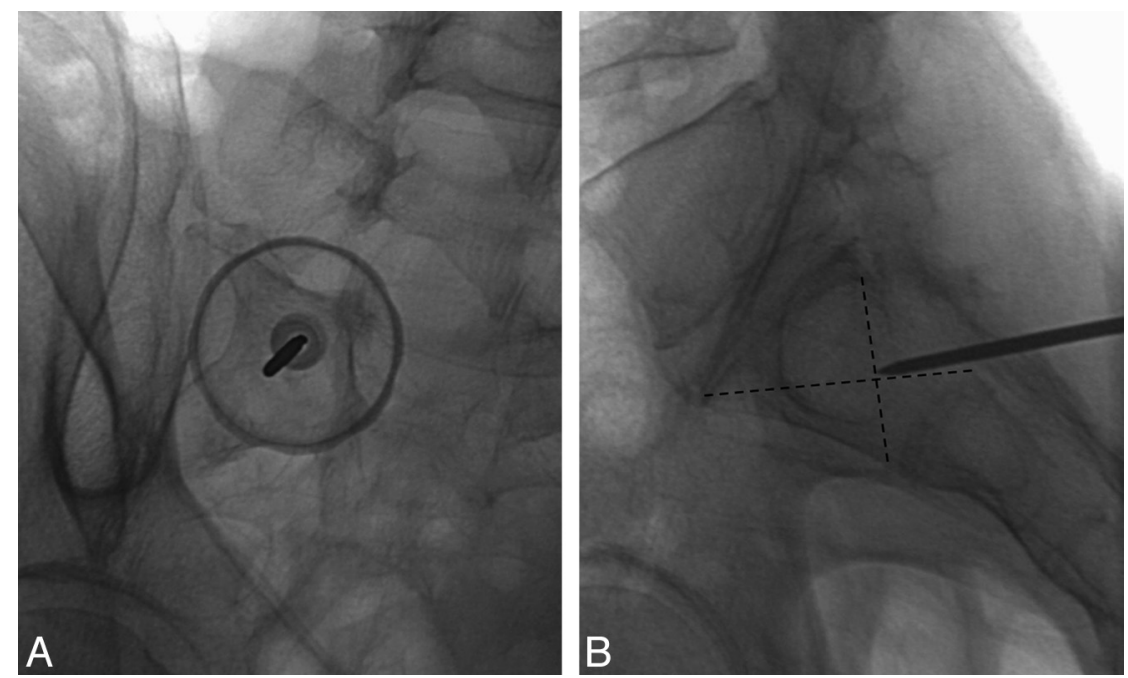

Fig 8. Prone oblique and lateral radiographs during left S1 sacroplasty by using the posterior approach demonstrate appropriate needle tip placement at the target point defined by Jayaraman et al. ${ }^{50}$
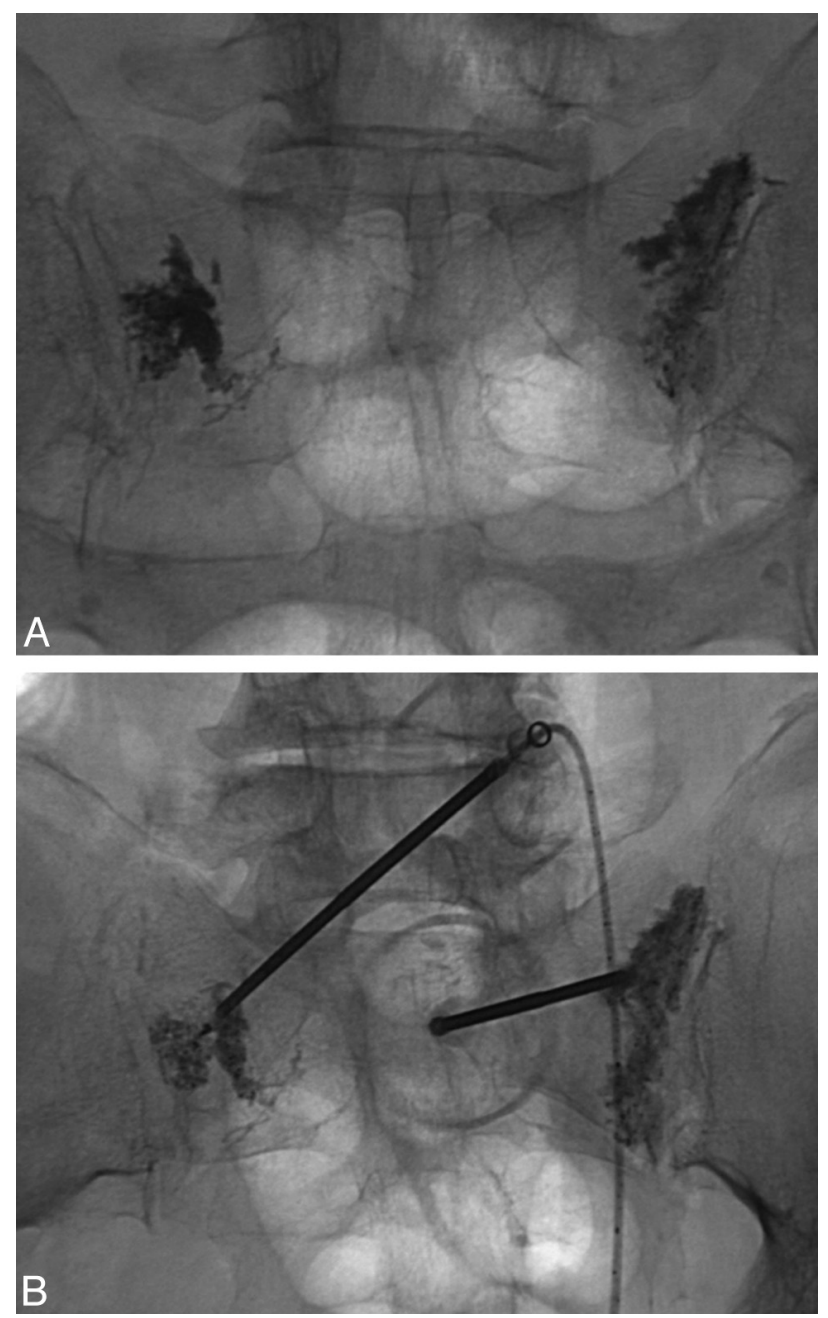

Fig 9. Postprocedural $(A)$ and intraoperative $(B)$ prone radiographs from posterior-approach sacroplasty demonstrate deposition of cement into the sacral ala.

rehabilitation. ${ }^{20,23}$ Although most patients improve symptomatically following conservative therapy, the time course can be prolonged and quite variable. Symptoms resolve in most patients by 12 months but can vary between 6 and 15 months. ${ }^{2,3,15,20,23}$

However, not all patients improve with conservative therapy, and prolonged bed rest is associated with significant morbidity, especially in the elderly. Of primary concern is thromboembolic disease, with a reported incidence of deep venous thrombosis following pelvic fracture between $29 \%$ and $61 \%$, and a $2 \%-12 \%$ incidence of pulmonary embolism. ${ }^{23}$ Other adverse sequelae associated with prolonged bed rest include loss of muscle mass, cardiac dysfunction, pneumonia, decubitus ulceration, and bone demineralization. ${ }^{23}$ In fact, half of patients with pelvic insufficiency fractures will not return to their prior functional level, and there is a reported $14.3 \%$ overall mortality. ${ }^{39}$

\section{Sacroplasty}

Sacroplasty has emerged as a minimally invasive alternative to conservative therapy for SIFs. Similar to vertebroplasty in the thoracolumbar spine, it involves injection of PMMA cement into the fractured sacrum under imaging guidance. ${ }^{5,6,40-42}$ The goal of sacroplasty is to provide early symptomatic relief, allowing more rapid mobilization. This would limit the need for significant narcotic analgesics, and lessen the risks associated with prolonged bed rest. Several retrospective and prospective case series suggest that sacroplasty can safely and effectively provide early symptomatic relief, ${ }^{5-7,41}$ though these findings have not been verified in controlled prospective randomized trials.

Injection of cement into the sacrum was first used for the therapy of painful bony metastases ${ }^{43,44}$ and was first described in sacral osteoporotic insufficiency fractures by Garant in 2002. ${ }^{40}$ Sacroplasty has increasingly been used for both these indications, though it has not yet achieved widespread acceptance, unlike vertebroplasty, probably due to the lack of validating controlled studies or because of unique technical considerations related to sacral anatomy.

The technical aspects of sacroplasty vary significantly between operators, including the technique of imaging guidance, as well as the needle approach. There are 2 basic needle approaches described in the literature: a posterior ap- 
proach $^{5,40-42,45}$ and the long-axis approach. ${ }^{36,46,47}$ A midline approach has also been used by some physicians to treat the horizontal or sacral body (zone 3) component of the fracture (F.R. Hellinger, unpublished data, 2009). Although the exact technique of these different approaches is beyond the scope of this article, a basic overview of the methodology and advantages of each is described.

\section{Posterior Approach}

The posterior or dorsal approach is similar to that in used in vertebroplasty, and many authors probably use this approach, given their familiarity with vertebroplasty. The patient is placed prone on the procedure table. Following the administration of a local anesthetic, an 11- or 13-gauge bone biopsy needle is percutaneously inserted through the posterior sacral cortex into the sacral ala and lateral aspect of the sacrum (zone 1) in a plane parallel to the sacroiliac joint (Figs 8 and 9). ${ }^{5,40}$ Often, 2-3 needles are inserted on a single side to ensure adequate dispersal of cement throughout the sacrum. On a fluoroscopic anteroposterior projection, the image intensifier is lined up parallel to the L5-S1 disk space and the ipsilateral sacroiliac joint. ${ }^{48}$ On the lateral fluoroscopic view, the ventral cortical margin can be difficult to discern because of the unique shape of the sacrum with its concave ventral surface. $^{5}$ Fluoroscopic landmarks have been confirmed with anatomic dissection and identify a well-defined triangular breach zone. ${ }^{49}$ Recently, a lateral target point for fluoroscopically guided sacroplasty has been described at the intersection of lines drawn through the corners of the S1 vertebral body (Fig 8). ${ }^{50}$ In our experience, acquiring a preoperative CT scan of the pelvis with multiplanar reformatted imaging is helpful to delineate the complex sacral anatomy for each patient.

One of the concerns with fluoroscopically guided sacroplasty is inadvertent transgression of the ventral sacral cortex by the procedure needle. Venography through the procedure needle has been suggested as a method to confirm needle tip placement, ${ }^{40}$ though other authors have found limited success by using this technique. ${ }^{5} \mathrm{CT}$ guidance allows accurate needle placement and allows the physician to remain confident that the needle tip remains intramedullary. Both $\mathrm{CT}^{5,47,51}$ and CT fluoroscopically ${ }^{41}$ guided sacroplasties have been described. However, observation of cement injection under fluoroscopy, either by using a mobile $\mathrm{C}$-arm or transfer of the patient to a fluoroscopy suite, is recommended because it is difficult to monitor cement extrusion on CT. ${ }^{41}$ This is especially true in the craniocaudal direction, which is the preferred direction of cement migration given the commonly vertically oriented sacral fractures.

\section{Long-Axis Approach}

The long-axis approach to sacroplasty involves placement of needles from caudal to cranial along the longitudinal extent of the sacrum. ${ }^{36,46,47}$ The patient is placed prone, and the image intensifier or CT gantry is tilted to align with the plane of the sacrum more closely. This technique offers 2 theoretic advantages over the posterior approach. First, placement of the procedure needles along the longitudinal extent of the sacrum removes the risk of inadvertent penetration of the ventral sacral cortex. Additionally, cement can be extruded from the procedure needle more evenly along the vertically oriented
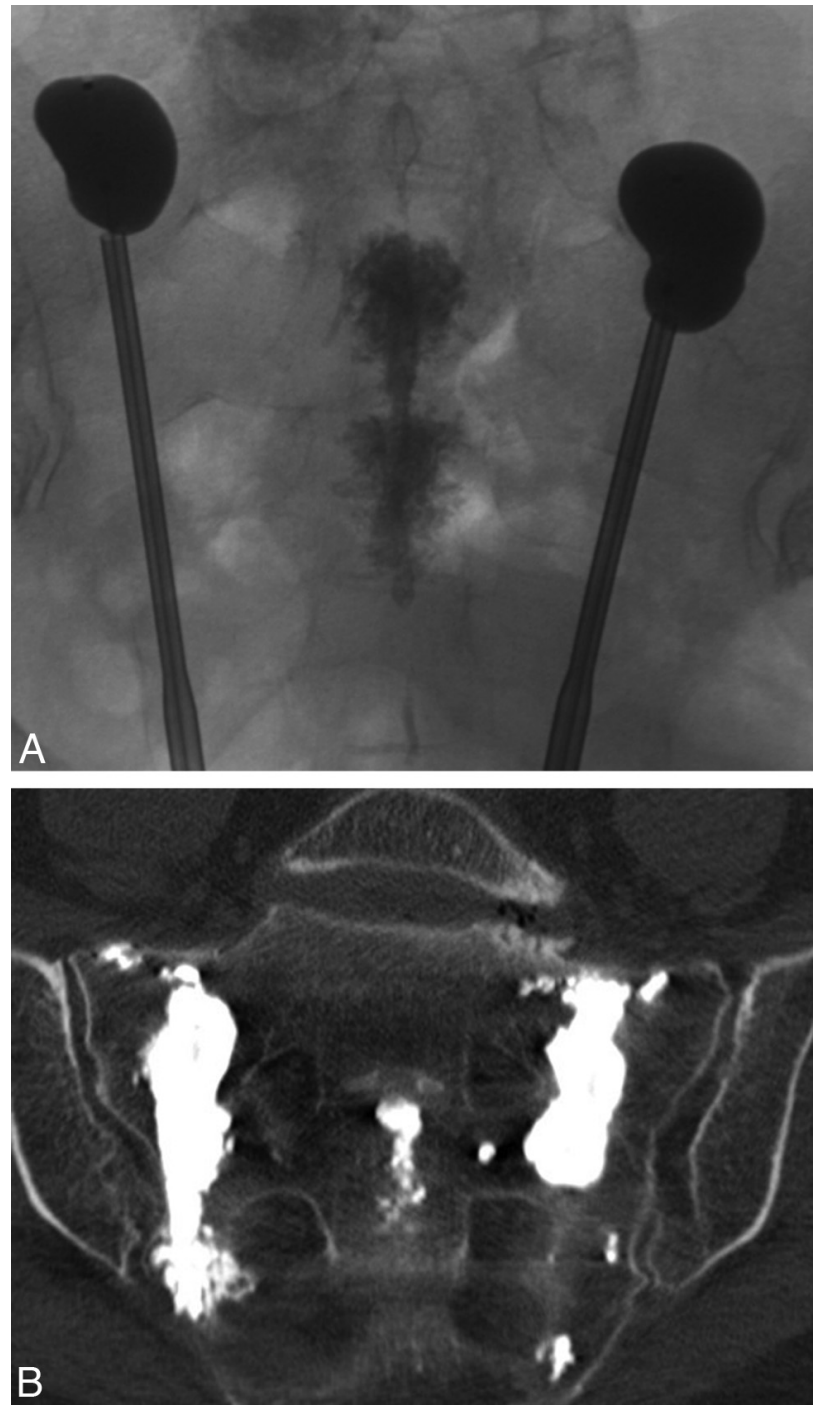

Fig 10. Intraoperative radiograph $(A)$ and postprocedural coronal oblique CT scan $(B)$ from long-axis-approach sacral kyphoplasty demonstrate more even deposition of PMMA cement along the lateral aspect of the sacrum. Note the cement within the sacral bodies from midline-approach sacroplasty, performed immediately prior. Courtesy of Frank R. Hellinger, Orlando General Hospital, Orlando, Florida.

sacral fractures, providing a more even distribution of cement rather than numerous relatively localized collections (Fig 10). Localized cement injections from the posterior approach also have a theoretically increased risk of early cement extravasation necessitating the delivery of smaller aliquots. Although the long-axis approach might intuitively appear advantageous, to our knowledge, the 2 techniques have not been compared in randomized controlled trials for safety and efficacy. To date, case series suggest that both techniques result in early symptomatic relief, with no significant reported complication. ${ }^{5,36,40,46}$

\section{Midline Approach}

Although the techniques described above address the fractures involving the sacral ala, a midline approach has been used by some physicians to treat the horizontal component of SIFs when present (F.R. Hellinger, unpublished data, 2009). With the patient prone, an 11-gauge needle is placed under fluoroscopic guidance from caudal to cranial in the midline parallel 


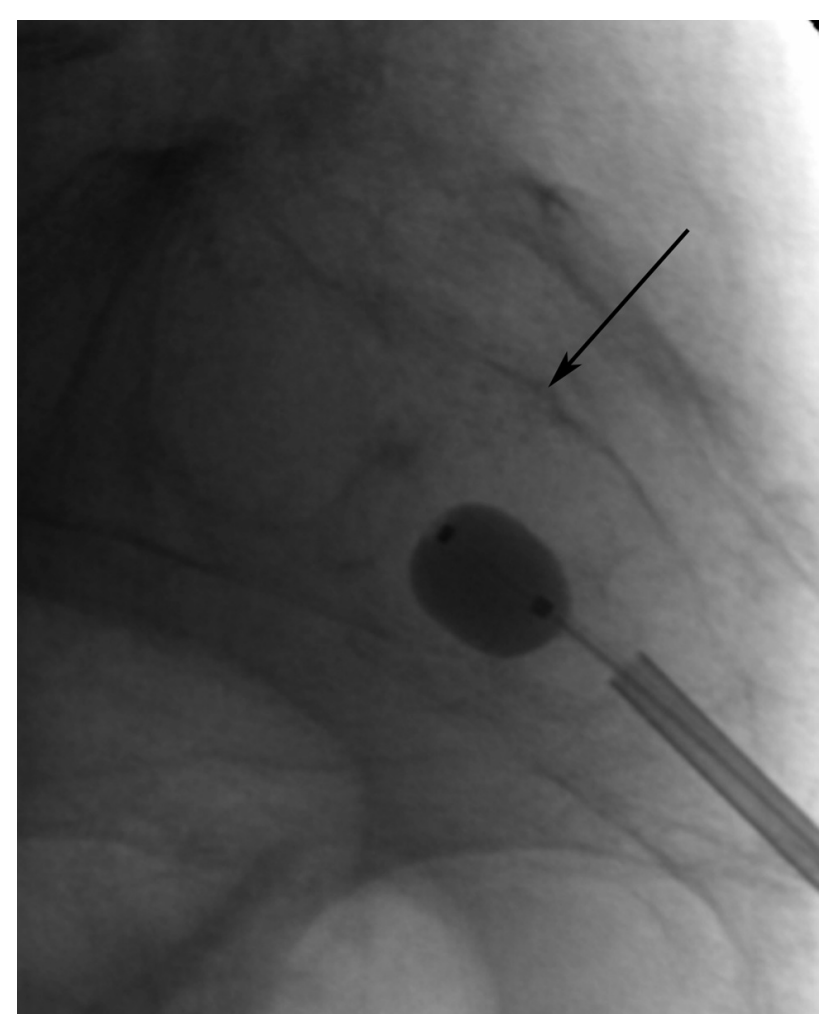

Fig 11. Lateral radiograph during inflation of a 10-mm balloon in an $S 2$ midline sacral body fracture (same patient as in Fig 12). Note that the dorsal cortical margin of the sacral body is well seen (black arrow). Courtesy of Frank R. Hellinger, Orlando General Hospital, Orlando, Florida.

to the plane of the sacrum (Fig 11). The needle transgresses the central sacral canal and necessitates a preprocedural MR imaging to verify that the expected needle tract is below the caudal extent of the thecal sac (Fig 12). One operator has performed 37 midline sacroplasties with no significant or permanent complications (F.R. Hellinger, unpublished data, 2009).

\section{Safety and Efficacy}

In multiple case series ${ }^{36,40-42,45-47}$ and a prospective multicenter trial, ${ }^{6}$ sacroplasty has provided early subjective symptomatic relief in patients treated for SIFs. The prospective study of 52 patients treated with sacroplasty found a $50 \%$ reduction in the VAS at 2 days, $80 \%$ at 2 weeks, and $90 \%$ at 1 year. ${ }^{6}$ Additionally, the authors found that reduction in the VAS paralleled the reduction in the use of narcotic medication. ${ }^{6}$ Other retrospective case series corroborate these results, reporting long-term pain relief following sacroplasty for as long as 1.5 years after the procedure. ${ }^{8}$ In addition, patients reported improved ability to perform activities of daily living. ${ }^{8}$ Although these results are promising, they have not been prospectively compared with those of a control group of patients treated with conservative therapy.

These results are similar to our experience. Between 2003 and 2008, 26 patients were treated at Wake Forest University Baptist Medical Center with sacroplasty. Early symptomatic pain relief was noted in almost all patients without any significant complications, and results have been published. ${ }^{5,8}$

In addition to osteoporotic fractures, sacroplasty has been used to treat painful metastatic lesions in the sacrum. ${ }^{43,44}$ Case

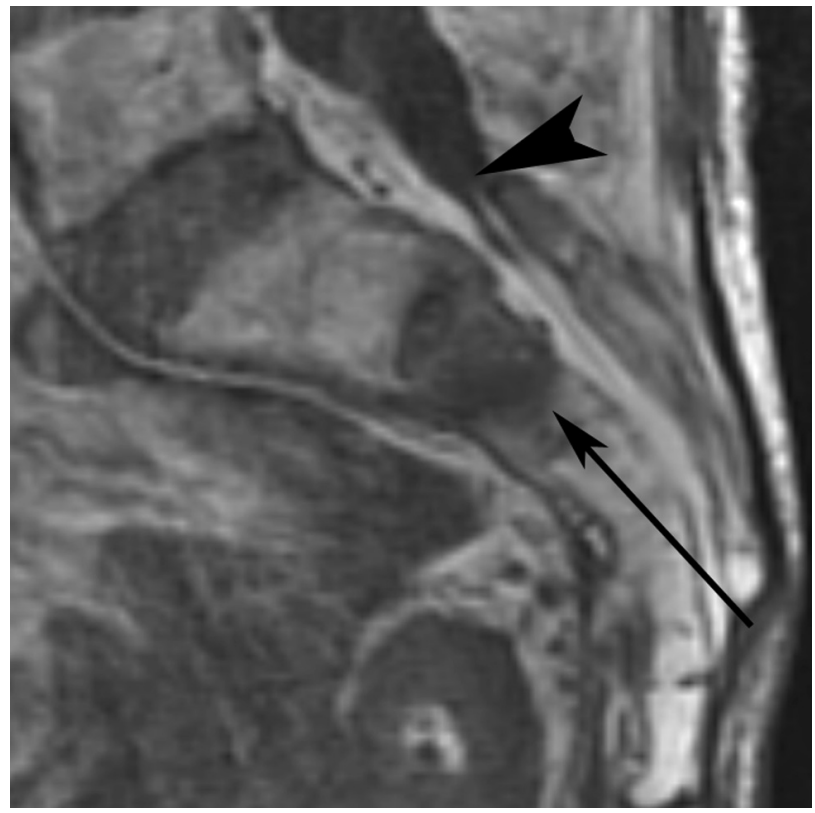

Fig 12. T1-weighted sagittal MR imaging of the sacrum demonstrates fracture-related edema in the S2 sacral body. Note that the thecal sac ends at the S2 level (black arrowhead), well above the expected needle path for the midline approach (thin black arrow). Note prior L5 and S1 laminectomies. Courtesy of Frank R. Hellinger, Orlando General Hospital, Orlando, Florida.

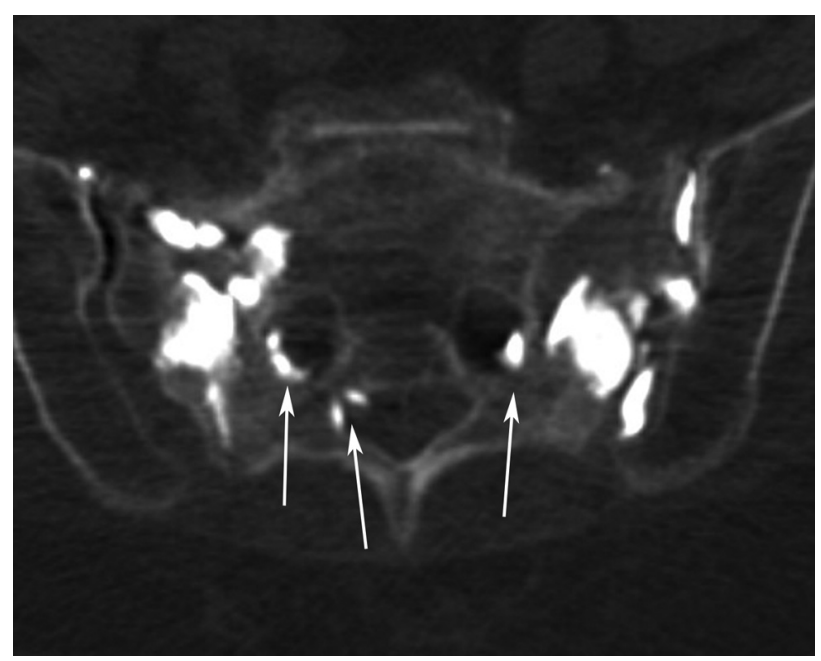

Fig 13. Axial CT scan following bilateral sacroplasty demonstrates leakage of PMMA cement into several sacral neural foramina and the left sacroiliac joint. Despite the extravasation, the patient was asymptomatic.

reports describe sacral cement injection for hepatocellular carcinoma, ${ }^{52}$ hemangioma, ${ }^{53}$ lung cancer and lymphoma, ${ }^{54}$ and renal cell carcinoma and myeloma. ${ }^{55}$

Complications of sacroplasty involve the unexpected extrusion of PMMA cement outside of the fractured sacrum, with untoward neurologic sequelae being the highest concern. Two cases of sacroplasty-associated cement leakage into the neural foramen have been described in the literature. ${ }^{6,42}$ In 1 case, there was a transient S1 neuritis, which resolved following transforaminal epidural steroid injection. ${ }^{6}$ Cement extrusion into the paraspinal soft tissues and sacroiliac joints can also be seen, though this is usually clinically insignificant unless it involves neural or vascular structures (Fig 13). Other 

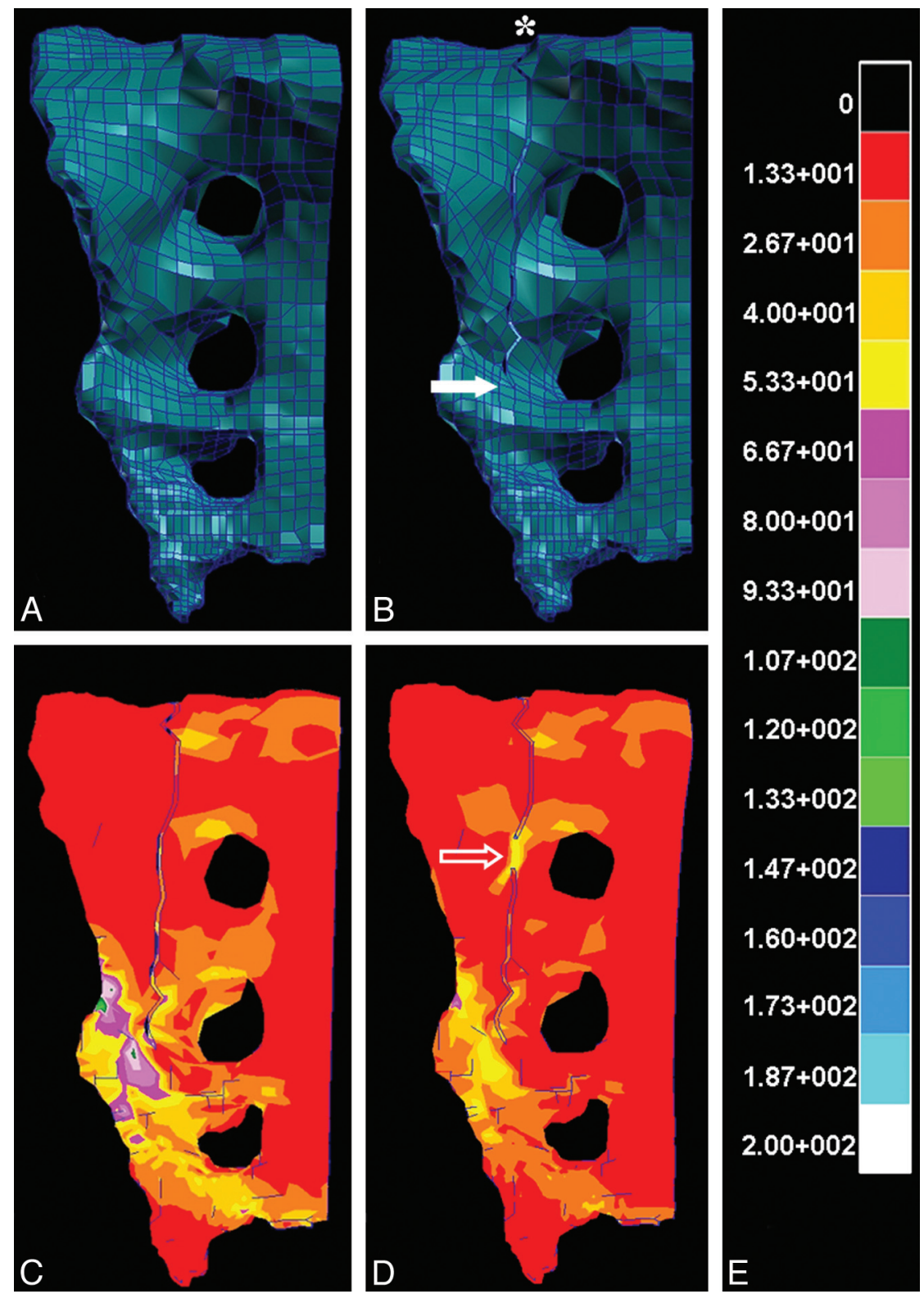

Fig 14. $A$ and $B$, Intact $(A)$ and fractured $(B)$ finite-element models of the hemisacrum constructed from cadaveric CT data, with the asterisk and solid arrow $(B)$ indicating fracture origin and point of fracture propagation, respectively. $C-E$, FEA reveals kilopascals of stress experienced by the hemisacrum after application of a $35-\mathrm{kg}$ load according to the calibration scale $(E)$, both before $(C)$ and after $(D)$ simulated sacroplasty at a point along the fracture (open arrow, D). Note that the point of fracture fusion (open arrow, $D$ ) subsumes a portion of the stress generated by the $35-\mathrm{kg}$ load and may explain the attenuated stress surrounding the site of fracture propagation compared with the presacroplasty model $(C)$.

theoretic complications of sacroplasty include extrusion of cement into the sacral spinal canal with associated neurologic compromise, infection, or venous emboli; however, to our knowledge, these have yet to be reported in the literature.

One technical consideration unique to sacroplasty involves the lack of resistance during cement extrusion. Unlike vertebral bodies during vertebroplasty, the capacious medullary cavity of the sacrum offers little resistance or feedback to the operator during cement extrusion. ${ }^{5,56}$ Close fluoroscopic monitoring is necessary to ensure that cement does not leak into the neural foramina, presacral space, or sacroiliac joint.

\section{Other Treatment Options}

Sacroplasty with balloon augmentation, or sacral kyphoplasty, has been described in 2 case reports suggesting the feasibility of this method. ${ }^{53,56}$ The sacral kyphoplasties were performed for osteoporotic fractures ${ }^{56}$ and a sacral hemangioma. ${ }^{53}$ Sacral kyphoplasty is technically similar to sacroplasty, and several balloon systems are commercially available. One suggested advantage of sacral kyphoplasty is the creation of a compacted bony layer outside the balloon, which could theoretically lower the likelihood of cement extravasation. ${ }^{56}$ One study evaluating balloon sacroplasty in cadaveric sacral models demonstrated more controlled localized deposition of cement. $^{49}$

Fluoroscopic placement of transiliosacral screws has also been reported in case series as an alternative method of sacral stabilization in patients with SIF. ${ }^{57}$ A similar procedure using computer assistance for screw placement has also been reported. $^{58}$ 


\section{Biomechanics}

Despite the subjective symptomatic relief experienced by patients, the exact mechanism of pain relief has not been fully elucidated. It has been suggested that excessive sheer strain on the sacral ala in insufficient bone results in fracture, with pain the result of micromotion at the fracture site. ${ }^{7}$ Biomechanical evaluation of cadaveric sacral models following sacroplasty has not shown any significant restoration of strength or stiffness following sacroplasty. ${ }^{16}$ Furthermore, the amount and location of PMMA cement used in sacroplasty has no bearing on the strength or stiffness restoration in cadaveric sacral models. ${ }^{59}$ However, these models assess the biomechanical properties of the entire sacrum and do not assess local biomechanical properties, especially near the cement-bone interface.

It has been suggested that sacral fracture stabilization and attenuation of fracture micromotion by the PMMA cement may underlie reports of sacroplasty-associated pain relief. FEA is an engineering method used to evaluate the mechanical properties of bone in computer-generated 3D geometric models of osseous structures. FEA has demonstrated an $83 \%$ decrease in maximal principal stress at the point of sacral fracture propagation in cadaveric sacral models after sacroplasty. FEA also demonstrated significantly diminished fracture gap micromotion after sacroplasty (Fig 14). ${ }^{48}$ Local compressive, tensile, and shear strains are also reduced $40 \%-60 \%$ following cement injection in nonfractured models, as documented by FEA. ${ }^{60}$ These biomechanical features may explain subjective pain relief following sacroplasty.

Sacroplasty has been criticized for disrupting normal osseous healing following sacral fracture. ${ }^{61,62}$ Tsiridis $^{62}$ noted that most patients with SIF recover completely with conservative therapy, albeit along an often prolonged and variable time course. Ehara ${ }^{61}$ suggested that sacroplasty may be more indicated in patients with delayed union or prolonged severe pain.

\section{Conclusions}

Sacral fractures are a common yet underdiagnosed cause of low back pain, predominantly in elderly women with osteoporosis. Plain radiographic, scintigraphic, $\mathrm{CT}$, and MR imaging findings have been well described in the literature. Bone scintigraphy and MR imaging are the most sensitive examinations and can be diagnostic, especially in the correct clinical setting. CT can be a helpful adjunct in cases in which scintigraphy and MR imaging are inconclusive.

Sacroplasty has recently emerged as a minimally invasive alternative to conservative treatment for SIFs. Prospective studies and case reports suggest that it is a safe and effective therapy, resulting in early symptomatic relief in patients with these fractures. However, randomized controlled trials comparing sacroplasty and conservative therapy are necessary to validate this technique.

The optimal technique for performing sacroplasty remains uncertain because various combinations of imaging guidance have been used and several different needle approaches have been described. Additionally, sacral kyphoplasty has been described. At this point in time, the exact technique used is dependent on the experience and comfort of the physician because all reported techniques have similar subjective pain relief and no significant reported complications. Still, studies comparing the safety and efficacy of the various techniques are necessary.

\section{Acknowledgments}

We thank Frank R. Hellinger, MD, PhD, Orlando General Hospital, Orlando, Florida, for technical advice regarding midline sacroplasty.

\section{References}

1. Lourie H. Spontaneous osteoporotic fracture of the sacrum: an unrecognized syndrome in the elderly. JAMA 1982;248:715-17

2. Gotis-Graham I, McGuigan L, Diamond T, et al. Sacral insufficiency fractures in the elderly. J Bone Joint Surg BR 1994;76:882-86

3. Peh WC, Khong PL, Ho WY, et al. Sacral insufficiency fractures: spectrum of radiological features. Clin Imaging 1995;19:92-101

4. Finiels H, Finiels PJ, Jacquot JM, et al. Fractures of the sacrum caused by bone insufficiency: meta-analysis of $\mathbf{5 0 8}$ cases [in French]. Presse Med 1997; 26:1568-73

5. Pommersheim W, Huang-Hellinger F, Baker M, et al. Sacroplasty: a treatment for sacral insufficiency fractures. AJNR Am J Neuroradiol 2003;24:1003-07

6. Frey ME, DePalma MJ, Cifu DX, et al. Percutaneous sacroplasty for osteoporotic sacral insufficiency fractures: a prospective, multicenter, observational pilot study. Spine J 2008;8:367-73. Epub 2007 Jul 20

7. Frey ME, DePalma MJ, Cifu DX, et al. Efficacy and safety of percutaneous sacroplasty for painful osteoporotic sacral insufficiency fractures: a prospective, multicenter trial. Spine J 2007;32:1635-40

8. Whitlow CT, Mussat-Whitlow BJ, Mattern CWT, et al. Sacroplasty versus vertebroplasty: comparable clinical outcomes for the treatment of fracturerelated pain. AJNR Am J Neuroradiol 2007;28:1266-70

9. De Smet AA, Neff JR. Pubic and sacral insufficiency fractures: clinical course and radiologic findings. AJR Am J Roentgenol 1985;145:601-06

10. Wild A, Jaeger M, Haak H, et al. Sacral insufficiency fracture: an unsuspected cause of low back pain in elderly women. Arch Orthop Trauma Surg 2002;122:58-60

11. Dasgupta B, Shah N, Brown H, et al. Sacral insufficiency fractures: an unsuspected cause of low back pain. Br J Rheumatol 1998;37:789-93

12. Peh WC, Khong PL, Sham JS, et al. Sacral and pubic insufficiency fractures after irradiation of gynaecological malignancies. Clin Oncol ( $R$ Coll Radiol) $1995 ; 7: 117-22$

13. Abe H, Nakamura M, Takahashi S, et al. Radiation-induced insufficiency fractures of the pelvis: evaluation with $99 \mathrm{~m}$ Tc-methylene diphosphonate scintigraphy. AJR Am J Roentgenol 1992;158:599-602

14. Blomlie V, Rofstad $\mathrm{E}$, Talle $\mathrm{K}$, et al. Incidence of radiation-induced insufficiency fractures of the female pelvis: evaluation with MR imaging. AJR Am J Roentgenol 1996;167:1205-10

15. Rawlings CE 3rd, Wilkins RH, Martinez S, et al. Osteoporotic sacral fractures: a clinical study. Neurosurgery 1988;22:72-76

16. Newhouse KE, El-Khoury GY, Buckwalter JA. Occult sacral fractures in osteopenic patients. J Bone Joint Surg Am 1992;74:1472-77

17. Weber M, Hasler P, Gerber H. Insufficiency fractures of the sacrum: 20 cases and review of the literature. Spine 1993;18:2507-12

18. West SG, Troutner JL, Baker MR, et al. Sacral insufficiency fractures in rheumatoid arthritis. Spine 1994;19:2117-21

19. Featherstone T. Magnetic resonance imaging in the diagnosis of sacral stress fracture. Br J Sports Med 1999;33:276-77

20. Lin J, Lachmann E, Nagler W. Sacral insufficiency fractures: a report of two cases and a review of the literature. J Womens Health Gend Based Med 2001;10:699-705

21. Muthukumar T, Butt SH, Cassar-Pullicino VN, et al. Cauda equina syndrome presentation of sacral insufficiency fractures. Skeletal Radiol 2007;36:309-13

22. Lundin B, Bjorkholm E, Lundell M, et al. Insufficiency fractures of the sacrum after radiotherapy for gynaecological malignancy. Acta Oncol 1990;29:211-15

23. Babayev M, Lachmann E, Nagler W. The controversy surrounding sacral insufficiency fractures: to ambulate or not to ambulate. Am J Phys Med Rehab 2000;79:404-09

24. Denis F, Davis S, Comfort T. Sacral fractures: an important problem. Clin Orthop Relat Res 1988;227:67-81

25. Leroux JL, Denat B, Thomas E, et al. Sacral insufficiency fractures presenting as acute low-back pain: biomechanical aspects. Spine 1993;18:2502-06

26. Kayanja M, Tsai E, Yamashita T, et al. The biomechanics of insufficiency fractures and augmentation of the sacrum. Spine J 2006;6(suppl):96

27. Peretz AM, Hipp JA, Heggeness MH. The internal bony architecture of the sacrum. Spine 1998;23:971-74

28. Grangier C, Garcia J, Howarth NR, et al. Role of MRI in the diagnosis of insufficiency fractures of the sacrum and acetabular roof. Skeletal Radiol 1997;26:517-24 
29. Peh WC, Khong PL, Yin Y, et al. Imaging of pelvic insufficiency fractures. Radiographics 1996;16:335-48

30. Cooper KL, Beabout JW, Swee RG. Insufficiency fractures of the sacrum. Radiology 1985;156:15-20

31. Blake SP, Connors AM. Sacral insufficiency fracture. Br J Radiol 2004; 77:891-96

32. Schneider R, Yacovone J, Ghelman B. Unsuspected sacral fractures: detection by radionuclide bone scanning. AJR Am J Roentgenol 1985;144:337-41

33. Ries T. Detection of osteoporotic sacral fractures with radionuclides. Radiology 1983;146:783-85

34. Fujii M, Abe K, Hayashi $K$, et al. Honda sign and variants in patients suspected of having a sacral insufficiency fracture. Clin Nucl Med 2005;30:165-69

35. Cabarrus MC, Ambekar A, Lu Y, et al. MRI and CT of insufficiency fractures of the pelvis and the proximal femur. AJR Am J Roentgenol 2008;191:995-1001

36. Smith DK, Dix JE. Percutaneous sacroplasty: long-axis injection technique. AJR Am J Roentgenol 2006;186:1252-55

37. Gacetta DJ, Yandow DR. Computed tomography of spontaneous osteoporotic sacral fractures. J Comput Assist Tomogr 1984;8:1190-91

38. Brahme SK, Cervilla V, Vint V, et al. Magnetic resonance appearance of sacral insufficiency fractures. Skelet Radiol 1990;19:489-93

39. Taillandier J, Langue F, Alemanni M, et al. Mortality and functional outcomes of pelvic insufficiency fractures in older patients. Joint Bone Spine 2003; 70:287-89

40. Garant M. Sacroplasty: a new treatment for sacral insufficiency fracture. J Vasc Interv Radiol 2002;13:1265-67

41. Butler CL, Given CA, Michel SJ, et al. Percutaneous sacroplasty for the treatment of sacral insufficiency fractures. AJR Am J Roentgenol 2005;184:1956-59

42. Heron J, Connell DA, James SL. CT-guided sacroplasty for the treatment of sacral insufficiency fractures. Clin Radiol 2007;62:1094-100

43. Dehdashti AR, Martin JB, Jean B, et al. PMMA cementoplasty in symptomatic metastatic lesions of the $\mathrm{S} 1$ vertebral body. Cadiovasc Intervent Radiol 2000;23:235-37

44. Marcy PY, Palussiere J, Magné N, et al. Percutaneous cementoplasty for pelvic bony metastases. Support Care Cancer 2000;8:500-03

45. Layton KF, Thielen KR, Wald JT. Percutaneous sacroplasty using CT fluoroscopy. AJNR Am J Neuroradiol 2006;27:356-58

46. Binaghi S, Guntern D, Schnyder P, et al. A new, easy, fast, and safe method for CT-guided sacroplasty. Eur Radiol 2006;16:2875-78

47. Strub WM, Hoffman M, Ernst RJ, et al. Sacroplasty by CT and fluoroscopic guidance: is the procedure right for your patient? AJNR Am J Neuroradiol 2007;28:38-41
48. Whitlow CT, Yazdani SK, Reedy ML, et al. Investigating sacroplasty: technical considerations and finite element analysis of polymethylmethacrylate infusion into cadaveric sacrum. AJNR Am J Neuroradiol 2007;28:1036-41

49. Betts A. Sacral vertebral augmentation: confirmation of fluoroscopic landmarks by open dissection. Pain Physician 2008;11:57-65

50. Jayaraman MV, Chang $H, A$ hn SA. An easily identifiable anatomic landmark for fluoroscopically guided sacroplasty: anatomic description and validation with treatment in 13 patients. AJNR Am J Neuroradiol 2009;30:1070-73. Epub 2009 Feb 4

51. Brook AL, Mirsky DM, Bello JA. Computerized tomography guided sacroplasty: a practical treatment for sacral insufficiency fracture-a case report. Spine 2005;30:450-54

52. Uemura A, Matsusako M, Numaguchi $Y$, et al. Percutaneous sacroplasty for hemorrhagic metastases from hepatocellular carcinoma. AJNR Am J Neuroradiol 2005;26:493-95

53. Atalay B, Caner H, Yilmaz C, et al. Sacral kyphoplasty for relieving pain caused by sacral hemangioma. Spinal Cord 2006;44:196-99

54. Zhang J, Wu C, Gu Y, et al. Percutaneous sacroplasty for sacral metastatic tumors under fluoroscopic guidance only. Korean J Radiol 2008;9:572-76

55. Wee B, Shimal A, Stirling AJ, et al. CT-guided sacroplasty in advanced sacral destruction secondary to tumour infiltration. Clin Radiol 2008;63:906-12. Epub 2008 May 14

56. Deen H, Nottmeier EW. Balloon kyphoplasty for treatment of sacral insufficiency fractures. Neruosurg Focus 2005;18:1-5

57. Scuibba DM, Wolinsky JP, Than KD, et al. CT fluoroscopically guided percutaneous placement of transiliosacral rod for sacral insufficiency fracture: case report and technique. AJNR Am J Neuroradiol 2007;28:1451-54

58. Tjardes T, Paffrath $\mathrm{T}$, Baethis $\mathrm{H}$, et al. Computer-assisted percutaneous placement of augmented iliosacral screws. Spine 2008;33:1497-500

59. Richards AM, Mears SC, Knight TA, et al. Biomechanical analysis of sacroplasty: does volume or location of cement matter? AJNR Am J Neuroradiol 2009;30:315-17. Epub 2008 Nov 6

60. Anderson DE, Cotton JR. Mechanical analysis of percutaneous sacroplasty using CT image based finite-element models. Med Eng Phys 2007;29:316-25. Epub 2006 May 24

61. Ehara S. Percutaneous sacroplasty for osteoporotic insufficiency fractures. AJR Am J Roentgenol 2006;186:580, author reply 580-81

62. Tsiridis E. Treatment of sacral insufficiency fractures. AJR Am J Roentgenol 2006;186:E21, author reply E21 